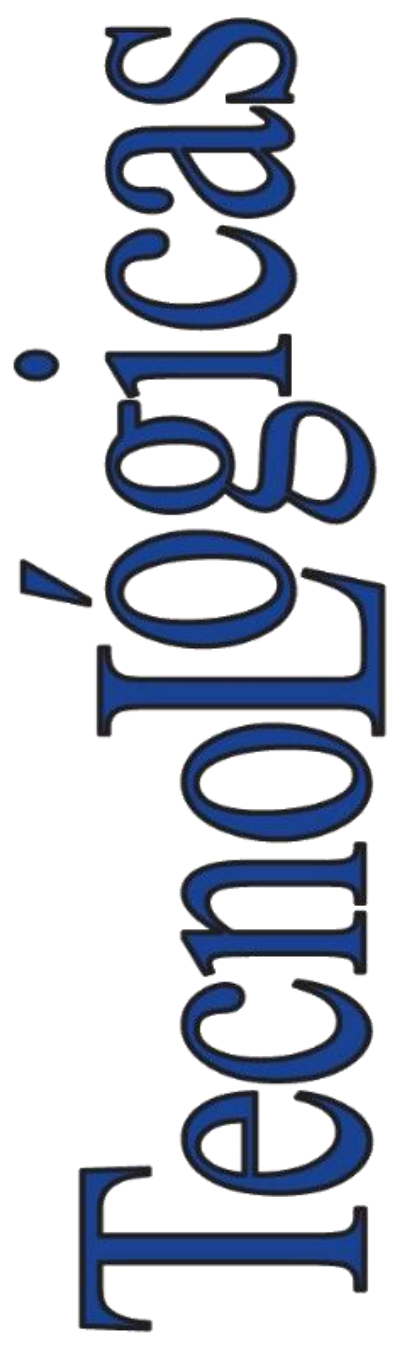

ISSN-p: 0123-7799 ISSN-e: $2256-5337$

Vol. 24, nro. 50, e1556

Recibido: 26 noviembre 2019 Aceptado: 16 septiembre 2020

Disponible: 30 octubre 2020

CInstituto Tecnológico Metropolitano Este trabajo está licenciado bajo una Licencia Internacional Creative Commons Atribución (CC BY-NC-SA)

\section{Diseño y control digital de un convertidor elevador entrelazado para sistemas de carga/descarga de baterías}

\section{Design and Digital Control of an Interleaved Boost Converter for Battery Charge/Discharge}

\author{
(D) Cristian Escudero-Quintero ${ }^{1}$; \\ (D) Santiago Acevedo²; \\ DJuan Pablo Villegas-Ceballos; \\ (D) Daniel González-Montoya ${ }^{4}$; \\ (D) Sergio I. Serna-Garcés ${ }^{5}$
}

\begin{abstract}
${ }^{1}$ Instituto Tecnológico Metropolitano, Medellín-Colombia, cristianescudero200038@itm.edu.co

${ }^{2}$ Instituto Tecnológico Metropolitano, Medellín-Colombia, santiagoacevedo176548@correo.itm.edu.co ${ }^{3}$ Instituto Tecnológico Metropolitano, Medellín-Colombia, juanvillegas@itm.edu.co ${ }^{4}$ Instituto Tecnológico Metropolitano, Medellín-Colombia, danielgonzalez@itm.edu.co ${ }^{5}$ Instituto Tecnológico Metropolitano, Medellín-Colombia, sergioserna@itm.edu.co
\end{abstract}

Cómo citar / How to cite

C. Escudero-Quintero; S. Acevedo; J. P. Villegas-Ceballos; D. GonzálezMontoya; S. I. Serna-Garcés, "Diseño y control digital de un convertidor elevador entrelazado para sistemas de carga/descarga de baterías", TecnoLógicas, vol. 24, nro. 50, e1556, 2021.

https://doi.org/10.22430/22565337.1556

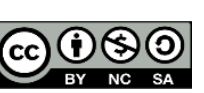




\title{
Resumen
}

Este trabajo presenta la metodología de diseño de un control digital para reducir el rizado en la corriente que se inyecta a la batería por medio de los convertidores que procesan la energía de carga y descarga, el cual es uno de los parámetros indicados en la literatura que disminuyen el tiempo de vida de las baterías. Este trabajo tiene como alcance mostrar el procedimiento de diseño e implementación de la estrategia propuesta sobre un convertidor entrelazado. La metodología implementada se presenta por medio de cuatro etapas (i) modelado del sistema batería-convertidor-carga, (ii) diseño de control digital basado en el modelo, (iii) diseño de la plataforma práctica donde se presenta la etapa de instrumentación e implementación utilizando un dispositivo embebido y (iv) la validación práctica del funcionamiento de la estrategia presentada y la disminución del rizado inyectado en la batería. Por medio de la metodología presentada se logra evidenciar el correcto desempeño del control digital cumpliendo los parámetros de diseño para diferentes modos de operación de carga de la batería y reduciendo el rizado de corriente en la batería entre un $50 \%$ a $65 \%$. Esta reducción protege la vida útil de la batería y de las fuentes o cargas conectadas al sistema. Adicionalmente, permite que los algoritmos de estimación de estado de carga y estado de salud incrementen su precisión, lo que conlleva a una mejora en los protocolos de mantenimiento y planificación de reemplazo de los elementos.

\section{Palabras clave}

Convertidor entrelazado; convertidor elevador; batería; control digital.

\begin{abstract}
According to the literature, battery ripple current is one of the phenomena that most significantly affect the state of health of batteries. Therefore, this paper presents a methodology to design a digital control in order to reduce such ripple current, which is injected by means of converters that process the charge and discharge energy. The strategy was designed for and implemented in an interlaced converter. The implemented methodology is presented in four stages: (i) modelling the battery-converter-charge system; (ii) designing the digital control based on the model; (iii) designing the practical implementation, where the instrumentation and implementation stage is presented using an embedded device; and (iv) practical validation of the operation of the strategy and the reduction of battery ripple current. The methodology presented here produced a correct performance of the digital control, fulfilling the design parameters of different operation modes and reducing the ripple current in the battery between 50 and $65 \%$. This reduction protects the battery's useful life and the sources or loads connected to the system. Additionally, it allows the state-of-charge and health estimation algorithms to increase their accuracy, which leads to an improvement in maintenance protocols and the planning of element replacement.
\end{abstract}

\section{Keywords}

Interleaved converter; boost converter; battery; digital control. 


\section{INTRODUCCIÓN}

La necesidad actual de disminuir la contaminación ambiental causada por los hidrocarburos ha impulsado el crecimiento en la investigación en diferentes áreas como los autos eléctricos [1], [2], [3], y las redes de generación de energías a partir de fuentes no convencionales [4]. Estas, a su vez, necesitan del desarrollo de otras tecnologías con el objetivo de mejorar sus propias necesidades, como lo son la autonomía, la confiabilidad y la reducción de costos de inversión y mantenimiento [5], [6].

Una de las tecnologías que más influye en el desarrollo de las necesidades en estas dos áreas son los sistemas de almacenamiento de energía (Energy Storage System - ESS), especialmente las baterías. Dentro de estas, las basadas en Ion-Litio son vistas como la tecnología más prometedora en este tipo de aplicaciones, debido a que poseen una alta densidad de potencia y energía, baja tasa de auto-descarga y un mayor número de ciclo de carga con respecto a las baterías basadas en plomo y níquel [7]. Sin embargo, las baterías son consideradas elementos críticos de operación debido al gran número de variables que aceleran su deterioro sin importar su tamaño, capacidad o tipo [8]. Este fenómeno de envejecimiento depende de las condiciones de almacenamiento y uso, dentro de las cuales intervienen variables como la temperatura [9], [10], las tasas de carga/descarga, la profundidad de descarga [8], las derivadas de corriente de carga [11] y el rizado en la corriente [2], [8], [12].

Este deterioro es típicamente medido por el índice de estado de salud (SOH por sus siglas en ingles), el cual mide porcentajes de variación de algunos parámetros de la batería indicando el grado de degradación [13], [14], [15]. El parámetro más utilizado para medir el $\mathrm{SOH}$ es la pérdida de capacidad de almacenamiento que ha sufrido la batería durante todo el tiempo de uso. Algunas de las variables que favorecen el deterioro de la batería pueden ser controladas por medio de dispositivos adicionales conocidos como sistema de gestión de batería (Battery Management System - BMS) [16], el cual mantiene las variables que intervienen en el proceso de carga/descarga dentro de los niveles de seguridad recomendados y además genera diagnósticos tempranos que evitan daños irreversibles en el proceso. Sin embargo, hay otras variables que no pueden ser controladas por el BMS, como es el caso del rizado de corriente presente en los dispositivos de potencia o convertidores conmutados usados comúnmente en los procesos de carga/ descarga de baterías [17], [18].

Una solución encontrada en la literatura para minimizar el rizado de conmutación es el uso de convertidores tipo elevador en configuración entrelazado [19], [20]. Este convertidor se caracteriza por la conexión en paralelo de dos convertidores elevadores, para el cual se pueden encontrar diferentes estrategias de control para su regulación de tensión y corriente. Otros autores, como en [21], proponen la conexión en paralelo de convertidores Buck con una relación maestro-esclavos, donde el maestro le impone las condiciones de corriente en estado estable a los esclavos conectados en paralelo, con el fin realizar una distribución de potencia que permita mantener la integridad de los convertidores y la demanda de potencia de la carga.

El maestro regula la tensión del bus, pero su corriente de salida no tiene un control, por lo que se producen sobre impulsos durante el transitorio. Este problema es solucionado con un control límite central que se encarga de controlar la corriente de cada rama en paralelo, prestando atención de que no sobrepasen la corriente de referencia límite central, la cual se define como la corriente de salida dividida el número de ramas. De esta manera, el sobre impulso de corriente a la salida se evita.

En este trabajo se presenta un diseño de la etapa de control digital para un convertidor elevador en configuración entrelazado, la cual permite despreciar el desbalance entre las ramas del convertidor y de este modo obtener el menor rizado posible. Adicionalmente, se presenta el diseño e implementación de la estrategia de control, la discretización del control 
y el convertidor entrelazado de dos ramas, el cual es comparado con el convertidor convencional elevador bidireccional utilizado en la carga y descarga de baterías [17], [18]. Posteriormente, se presenta la implementación de los dos controles y su comparación. En la sección final se presentan las conclusiones del trabajo.

\section{Planteamiento del PROBlema}

Un convertidor entrelazado se caracteriza por tener dos convertidores conectados en paralelo conmutando a la misma frecuencia y con un cambio de fase entre las señales de control. Esta técnica tiene como resultado una disminución en el rizado de las formas de onda de entrada y salida y un menor contenido de armónicos [22]. Además, las pérdidas de conmutación y conducción, así como los niveles de interferencia electromagnética (EMI), disminuyen significativamente en el modo de operación entrelazado [23]. La cancelación resultante de armónicos de baja frecuencia permite, eventualmente, la reducción del tamaño y las pérdidas en las etapas de filtrado [22].

Se pueden encontrar en la literatura diferentes estrategias de control de un convertidor entrelazado. Los autores en [24], [25] presentan el diseño y simulación de un control PID para un convertidor entrelazado con dos ramas unidireccionales. Para este mismo convertidor, pero con tres ramas, los autores en [1] implementan un controlador PI para la regulación de una celda de combustible para un vehículo eléctrico. Otros autores, como en [26], han evaluado las ventajas de un convertidor entrelazado en el tiempo de vida de las celdas de combustible y el rendimiento de un control LQR sobre el convertidor. Los autores en [27] presentan una estrategia de control por modos deslizantes para la regulación del voltaje de salida del convertidor. La mayoría de estos trabajos recomiendan el uso de la misma señal de control para todas las ramas del convertidor con una simple modificación en la fase para cada una de las señales, calculada como 360/n, donde n representa el número de ramas del convertidor.

Esto lleva a necesitar un desfase de $180 \%$ o $50 \%$ y un ciclo útil de $50 \%$ para un convertidor de 2 ramas, logrando una reducción de casi el 100 \% para una razón entre los voltajes de entrada y salida igual a dos. Esta reducción no se cumple si se buscan relaciones de elevación diferentes al doble de la tensión de entrada; por ejemplo, elevar de $12 \mathrm{~V}$ a $48 \mathrm{~V}$ o de $12 \mathrm{~V}$ a $36 \mathrm{~V}$, como puede darse en algunos rangos de operación de microrredes en DC con elementos almacenadores de $12 \mathrm{~V}$ de tensión nominal que requieren ser conectados a un bus de DC principal [28]. Además, debido al desbalance presente en las ramas del convertidor, producto de la tolerancia en los valores de los elementos, las pérdidas de conducción y el diseño del circuito impreso, se generan niveles DC y rizados diferentes en las corrientes de las ramas del convertidor, las cuales son también condiciones necesarias para la reducción del rizado en un convertidor entrelazado. Por lo tanto, debe efectuarse un diseño tanto de un convertidor que permita la reducción del rizado de corriente, como es el caso de la topología entrelazada, como un sistema de control que regule la tensión de salida a los niveles requeridos. Para llevar a cabo esta última labor en una topología entrelazada, se debe diseñar un controlador para cada rama y asegurar que tienen un desfase en su acción de control para asegurar la reducción del rizado en la corriente que fluye en la batería. En este trabajo se presenta el proceso de diseño de un controlador digital para un convertidor elevador entrelazado, cumpliendo con los criterios anteriormente expuestos. 


\section{SOLUCIÓN PROPUESTA}

Uno de los convertidores más utilizados en el proceso de carga/descarga de una batería es el convertidor elevador, debido a su simplicidad y alto rango de conversión [17], [18], [20].

Este tipo de convertidor permite acoplar los niveles de tensión de la batería a los niveles de tensión del bus DC manteniendo este constante y controlando las perturbaciones presentadas debido a la conexión y desconexión de cargas y fuentes de energía. Sin embargo, el rizado de corriente generado en la conmutación es transferido a la batería, generando pérdidas de potencia y deterioro en la batería.

Como solución se ha utilizado una tipología conocida como intercalada, donde se conectan más de dos convertidores en paralelo y se desfasan las señales de conmutación con el objetivo de reducir el rizado en la corriente siguiendo (1), donde $\mathrm{N}$ representa el número de convertidores conectados.

$$
\theta_{k}=\frac{(k-1) * 360}{N} ; k=1, \ldots, N-1
$$

La Figura 1 muestra un convertidor entrelazado, donde se puede observar que por cada una de las ramas circula solo una porción de la corriente total de la batería, lo cual disminuye las corrientes máximas que pasa por los inductores, lo que permite reducir los límites de la corriente de saturación del núcleo de las bobinas, el cual es uno de las características que aumenta el precio de las mismas.

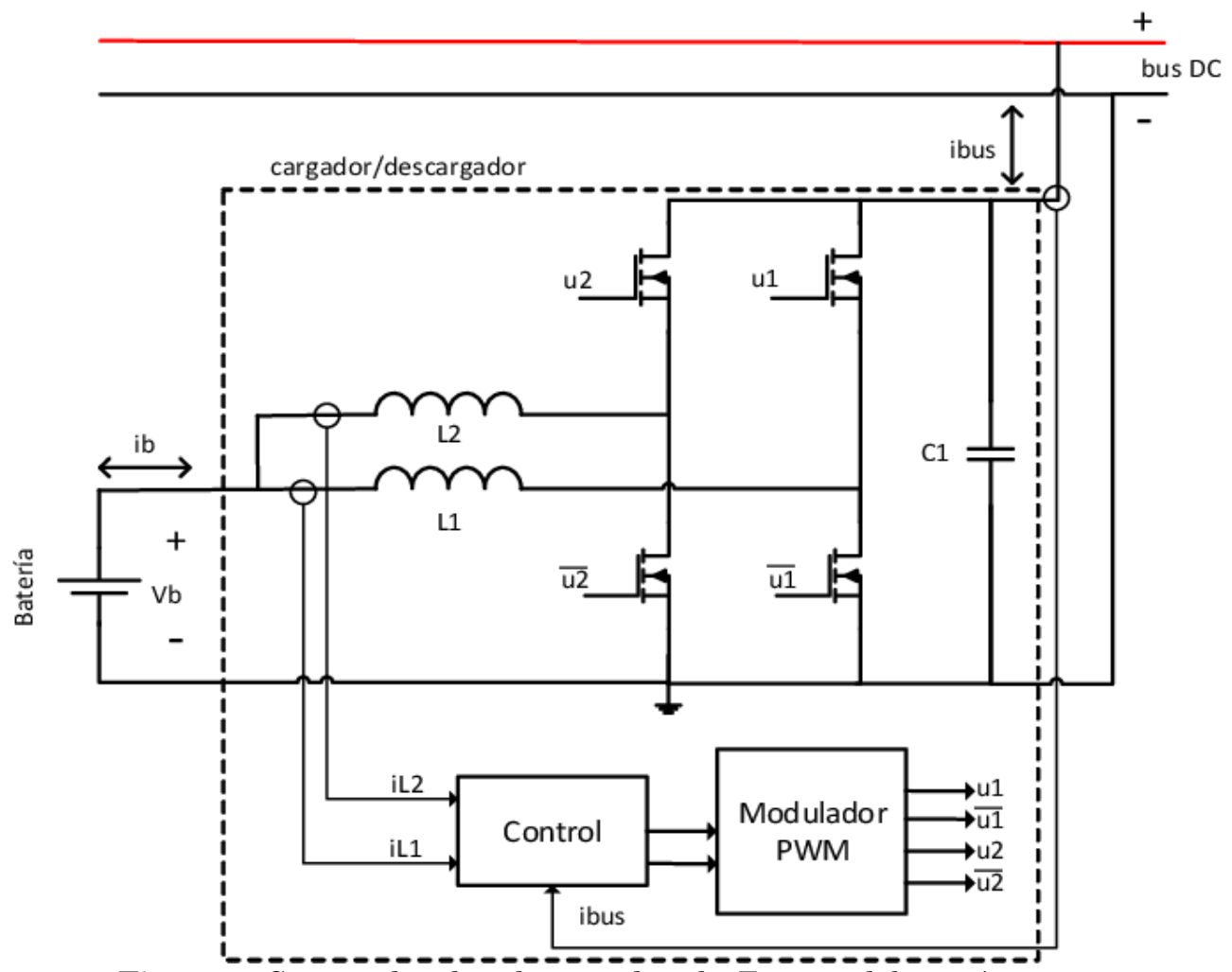

Figura 1. Convertidor elevador entrelazado. Fuente: elaboración propia. 
Las ecuaciones diferenciales (2), (3) y (4) representan las variaciones que sufren en el tiempo las variables de estado del convertidor (corrientes en la bobina $i_{L 1}, i_{L 2}$ y voltaje en el capacitor de salida $v_{c}$ ), las cuales son encontradas utilizando el mismo método utilizado en el convertidor elevador descrito en [29].

$$
\begin{gathered}
\dot{v}_{c}=\frac{i_{\mathrm{L}_{1}}\left(1-\mathrm{u}_{1}\right)+i_{\mathrm{L}_{2}}\left(1-\mathrm{u}_{2}\right)-i_{\mathrm{bus}}}{\mathrm{C}_{1}} \\
\iota_{\mathrm{L} 1}=\frac{v_{\mathrm{b}}-v_{\mathrm{dc}}\left(1-\mathrm{u}_{1}\right)}{\mathrm{L}_{1}} \\
l_{\mathrm{L} 2}=\frac{v_{\mathrm{b}}-v_{\mathrm{dc}}\left(1-\mathrm{u}_{2}\right)}{\mathrm{L}_{2}}
\end{gathered}
$$

A partir de estas ecuaciones se conforma el espacio de estado del sistema mostrado en (5), (6) y (7), las cuales representadas en su forma canónica $X=A \dot{X}+B U$ :

$$
\begin{gathered}
\mathbf{X}=\left[\begin{array}{l}
v_{c 1} \\
i_{L 1} \\
i_{L 2}
\end{array}\right], \mathbf{U}=\left[\begin{array}{c}
d_{1} \\
d_{2} \\
i_{\text {bus }} \\
v_{\text {bat }}
\end{array}\right] \\
\boldsymbol{A}=\left[\begin{array}{cccc}
0 & \frac{\left(1-\mathrm{D}_{1}\right)}{\mathrm{C}_{1}} & \frac{\left(1-\mathrm{D}_{2}\right)}{\mathrm{C}_{1}} \\
\frac{-\left(1-\mathrm{D}_{1}\right)}{\mathrm{L}_{1}} & 0 & 0 \\
\frac{-\left(1-\mathrm{D}_{2}\right)}{\mathrm{L}_{2}} & 0 & 0
\end{array}\right] \\
\boldsymbol{B}=\left[\begin{array}{cccc}
\frac{-\mathrm{Ibus}}{\left(2-2 \mathrm{D}_{1}\right) \mathrm{C}_{1}} & \frac{-\mathrm{Ibus}}{\left(2-2 \mathrm{D}_{2}\right) \mathrm{C}_{1}} & \frac{-1}{\mathrm{C}_{1}} & 0 \\
\frac{\mathrm{V}_{\mathrm{bat}}}{\left(1-\mathrm{D}_{2}\right) \mathrm{L}_{1}} & 0 & 0 & \frac{1}{L_{1}} \\
0 & \frac{\mathrm{V}_{\text {bat }}}{\left(1-\mathrm{D}_{1}\right) \mathrm{L}_{2}} & 0 & \frac{1}{L_{2}}
\end{array}\right]
\end{gathered}
$$

A partir de este espacio de estados es posible obtener 12 funciones de transferencia del sistema, de las cuales solo se usan las funciones de las variables a controlar. Para controlar el voltaje de bus y poder reducir el rizado de corriente en la batería se utiliza la estructura de control presentada en la Figura 2, donde se puede observar que es necesario medir las tres variables de estado del sistema.

La estructura de control es seleccionada debido a que la función de transferencia del voltaje del bus DC con respecto a la entrada $d_{1}$ presenta un comportamiento de fase no mínima impidiendo un control directo del voltaje, por lo cual es necesario implementar un control en modo de corriente, comprendido por un control interno de corriente $G_{c_{1}}$ y un control 
de voltaje externo $G_{c_{3}}$. Una tercera estructura de control es utilizada para realizar una perfecta sincronización entre las corrientes de las dos ramas, la cual tiene la misma estructura de $G_{c_{1}}$ y es diseñada utilizando la función de transferencia $i_{L_{2}} / d_{2}$.

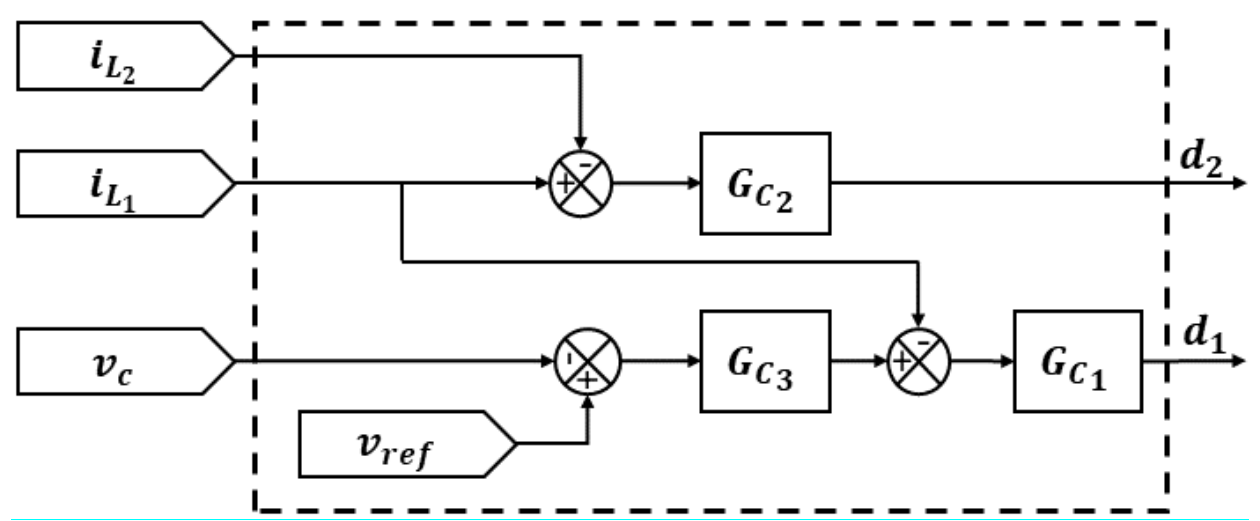

Figura 2. Diagrama de flujo del controlador PI para el convertidor elevador entrelazado Fuente: elaboración propia.

A partir de las ecuaciones de estado se encuentran los valores de los componentes siguiendo el procedimiento mostrado en [29], utilizando como parámetros de diseño los valores de rizados en la corriente en cada rama $\Delta i_{r}=0.2 \mathrm{~A}$, rizado en el voltaje de $\Delta v=0.1 \mathrm{~V}$, voltaje en la batería $V_{b a t}=12 \mathrm{~V}$, voltaje en el bus DC $V_{d c}=24 \mathrm{~V}$, corriente en el bus $I_{b u s}=1 \mathrm{~A}$, ciclos útiles $D_{1}=0.5$ y $D_{2}=0.5 \mathrm{y}$ frecuencia de conmutación de $100 \mathrm{kHz}$, obteniendo valores de $C_{1}=44 u F$ y $L_{1,2}=330 u F$.

Para convertir el modelo al tiempo discreto se utiliza una transformación bilineal con una frecuencia de muestreo de $200 \mathrm{kHz}$ para cumplir el teorema de muestreo de Nyquist-Shannon, obteniendo la función de transferencia de las dos corrientes del inductor expresada en (8) y la función del voltaje $v_{c}$ en función de la corriente $i_{L_{2}}$ expresada en (9).

$$
\begin{gathered}
\frac{i_{L_{k}}}{d_{k}}(z)=\frac{0.1818-0.1818 z^{-1}-0.1818 z^{-2}+0.1818 z^{-3}}{1-3 z^{-1}+3 z^{-2}-z^{-3}} \\
\frac{v_{c}}{i_{L_{1}}}(z)=\frac{1.062 \times 10^{-8}+2.124 \times 10^{-9} z^{-1}+1.274 \times 10^{-8} z^{-2}}{1-2 z^{-1}+z^{-2}}
\end{gathered}
$$

A partir de estas tres funciones de transferencia se diseñan los controladores siguiendo el procedimiento descrito en [30], utilizando como criterios de diseño un factor de amortiguamiento de 0.707 y un tiempo de establecimiento inferior a $2 \mathrm{~ms}$ para el control de voltaje y $1 \mathrm{~ms}$ para el control de corriente. Debido a que el control de voltaje debe ser más lento que el control interno, se selecciona una frecuencia de corte de la quinta parte de la frecuencia de conmutación, la cual es fijada a $100 \mathrm{kHz} / 5=20 \mathrm{kHz}$. La función de transferencia de los tres controladores diseñados se muestra en (10) y (11).

$$
G_{c_{1,2}}(z)=\frac{0.2908-0.2798 z^{-1}}{1-z^{-1}}
$$




$$
G_{C_{3}}(z)=\frac{0.04428-0.04333 z^{-1}}{1-z^{-1}}
$$

\section{RESULTADOS Y DISCUSIÓN}

Para la simulación e implementación del control digital se llevan las funciones de transferencia de control a ecuaciones en diferencias para una implementación en cualquier dispositivo programable. Este proceso consiste en realiza la transformada z inversa a (10) y (11), obteniendo de esta forma (12) - (15), donde $e_{i} y e_{v}$ son el error de corriente y error de voltaje, respectivamente, expresadas mediante (13), (14) y (16), donde (n) indica la iteración actual y $(n-1)$ una iteración anterior.

$$
\begin{gathered}
d_{1,2}(n)=0.2908 e_{i_{1,2}}(n)-0.2788 e_{i_{1,2}}(n-1)+d_{1,2}(n-1) \\
e_{i_{1}}(n)=i_{L_{1}}(n)-i_{L_{2}}(n) \\
e_{i_{2}}(n)=i_{L_{r e f}}(n)-i_{L_{1}}(n) \\
i_{L_{r e f}}(n)=0.04428 e_{v}(n)-0.04333 e_{v}(n-1)+i_{L_{r e f}}(n-1) \\
e_{v}(n)=v_{r e f}(n)-v_{c}(n)
\end{gathered}
$$

\subsection{Simulación del control digital}

En la simulación se utilizan los mismos valores de los elementos utilizados en el proceso del diseño de control. Adicionalmente, el procedimiento de diseño se desarrolla para voltaje en el bus de $36 \mathrm{~V}$ y $48 \mathrm{~V}$ con el objetivo de validar la implementación del control con diferentes puntos de operación. Para obtener resultados similares a la implementación real, el control es implementado utilizando bloques de código en el lenguaje $\mathrm{C}$ y las ecuaciones en diferencias.

Para poder comprobar la respuesta del control frente a las perturbaciones, estas se aplican al sistema de escalones de corriente en el bus DC para simular el proceso de carga y descarga del convertidor, con perturbaciones de corrientes de $1 \mathrm{~A}, 1.5 \mathrm{~A}$ y $2 \mathrm{~A}$ tanto positivos como negativos con intervalos de $30 \mathrm{~ms}$, como se muestra en la Figura 3.

La Figura 4, muestra la respuesta del controlador para una referencia del voltaje del bus DC de $24 \mathrm{~V}$, exactamente el doble del voltaje de la batería, donde se puede observar un correcto seguimiento de la corriente $I_{L_{2}}$ a su referencia $I_{L_{1}}$. Adicionalmente, se observa una minimización en el rizado de corriente de la batería con respecto a un convertidor elevador convencional. Caso diferente se observa para la sintonización del control para referencias de voltaje en el bus de $36 \mathrm{~V}$ y $48 \mathrm{~V}$, donde no se logra una minimización igual de la corriente como se puede ver en la Figura 5 comparado con la casi anulación de rizado lograda para la referencia de $24 \mathrm{~V}$. Sin embargo, se puede observar que el control regula correctamente el voltaje dado por la referencia, y las corrientes de las dos ramas siguen perfectamente la referencia correspondiente. Adicionalmente, se observa una disminución en el rizado del voltaje del bus para las tres referencias, comparado con el resultado obtenido con el convertidor elevador. 


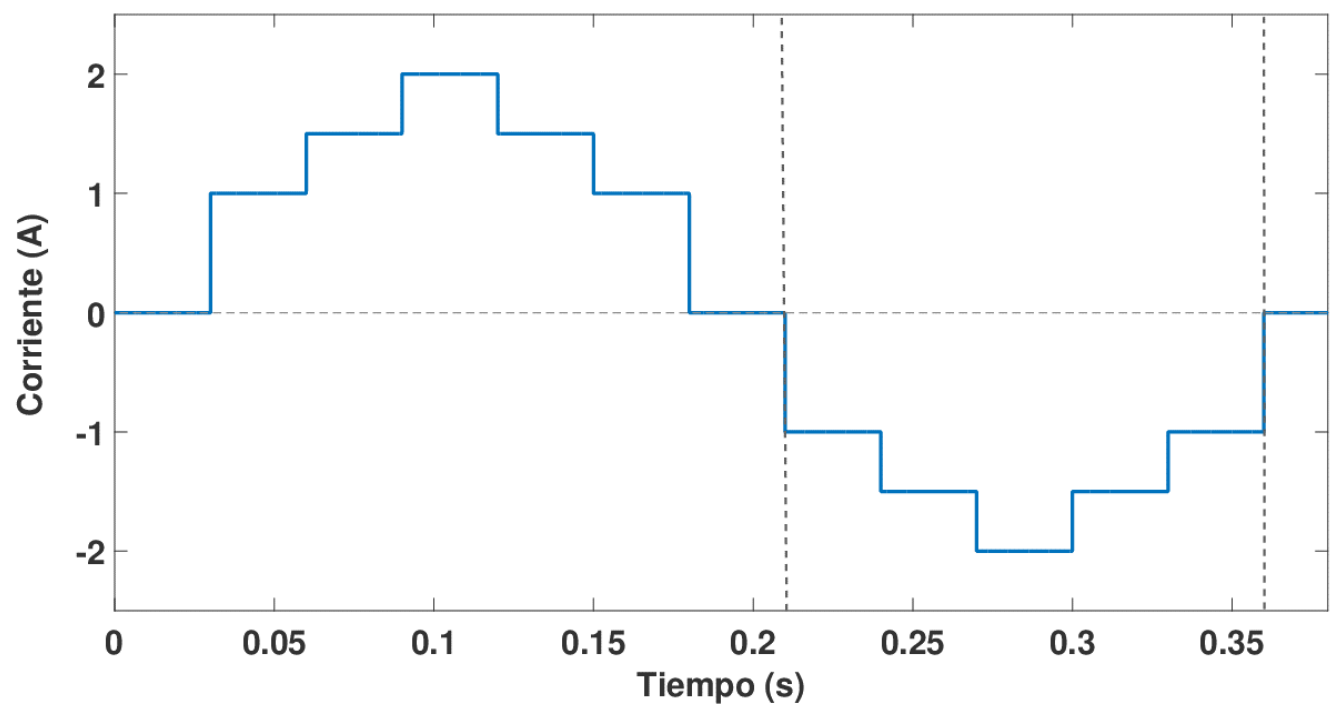

Figura 3. Escalones de corriente del bus DC. Fuente: elaboración propia.
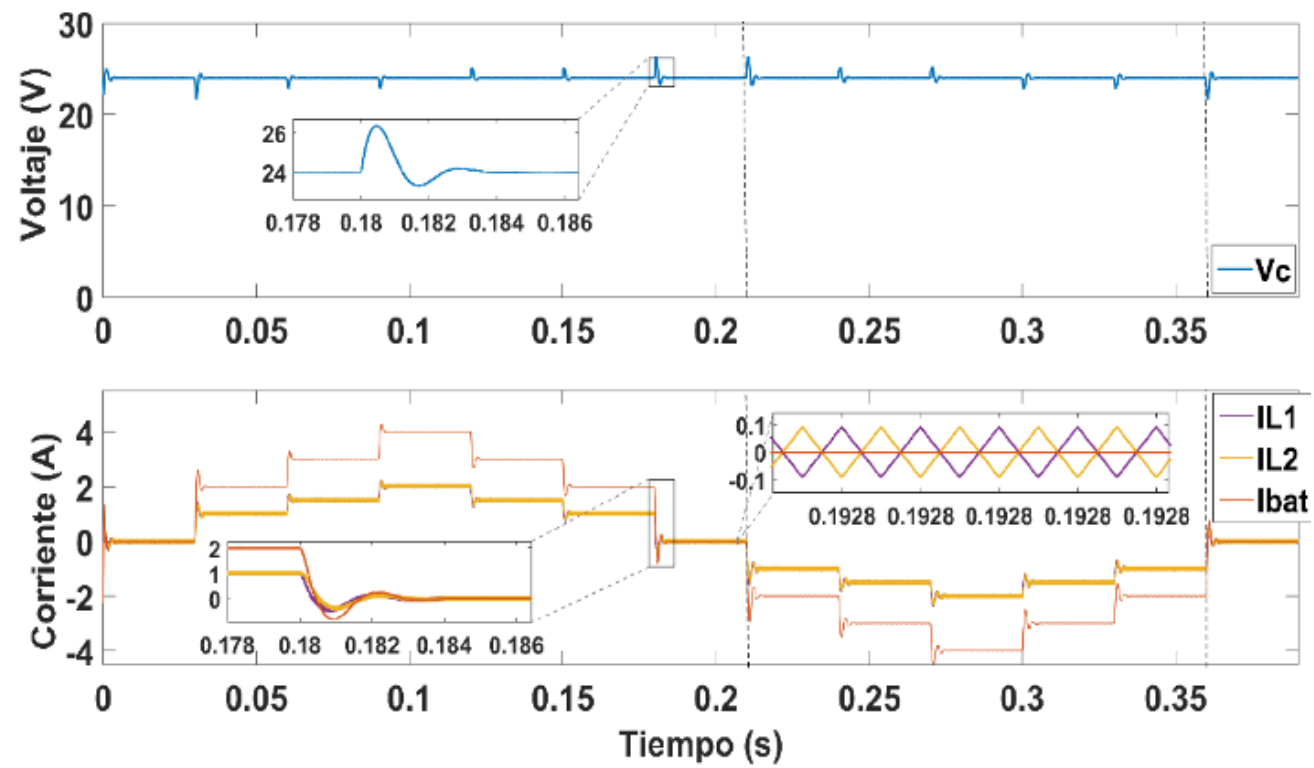

Figura 4. Respuesta del controlador PI para un convertidor elevador entrelazado con referencia de $24 \mathrm{~V}$ Fuente: elaboración propia.

\subsection{Implementación del control digital}

La implementación del control es desarrollada sobre el microcontrolador de 32 bits de Texas Instruments TMS320F28335 [31]. La Figura 6, presenta un esquema simplificado de los elementos más importantes del dispositivo utilizados en la implementación.

El microcontrolador cuenta con un ADC de 12 bits con 16 canales de muestreo múltiple. Para esta implementación se utilizan 3 canales para muestrear $i_{L_{1}}, i_{L_{2}} y v_{c}$. Adicionalmente, el módulo ADC es configurado con un reloj de $25 \mathrm{MHz}$, por medio de los registros, lo que permite muestras cada $40 \mathrm{~ns}$, las cuales son almacenadas en los registros de memoria destinados para cada uno de los canales del conversor (registros 0x70A8 a 0x70B7 en memoria). 


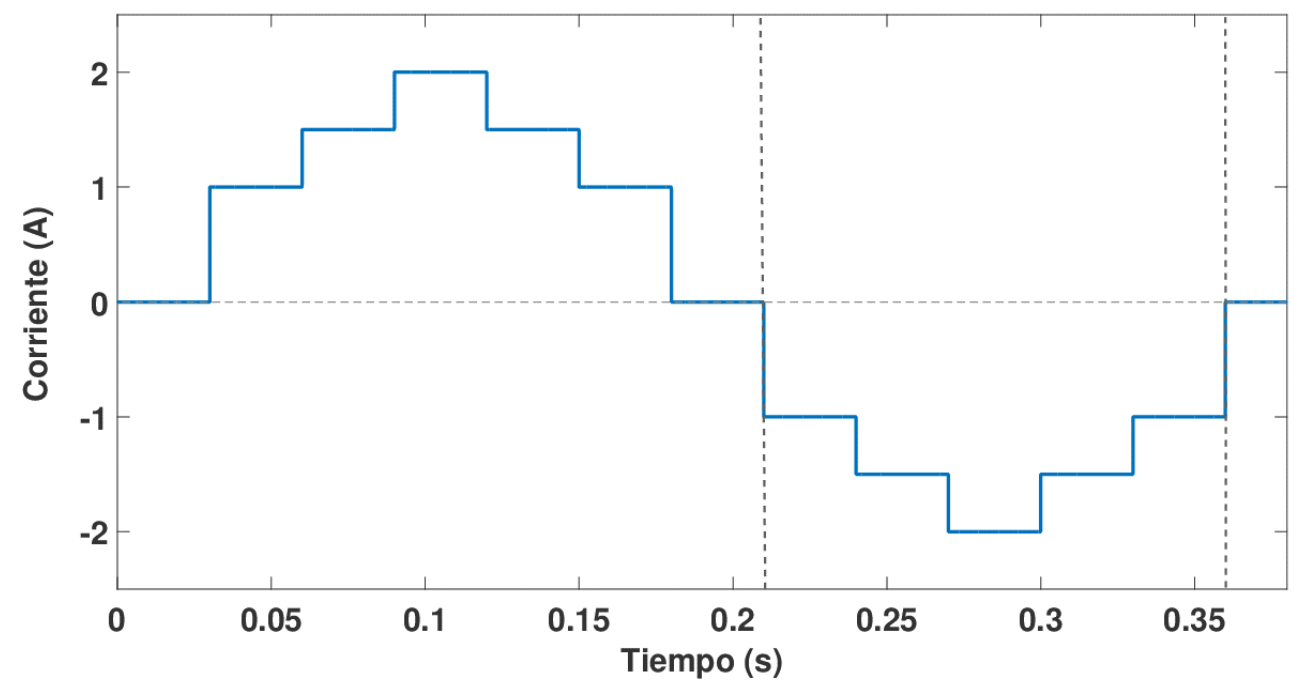

Figura 5. Comparación de la respuesta de un control PI de un elevador entrelazado para voltajes de referencia de $24 \mathrm{~V}, 36 \mathrm{~V}$ y $48 \mathrm{~V}$. Fuente: elaboración propia.
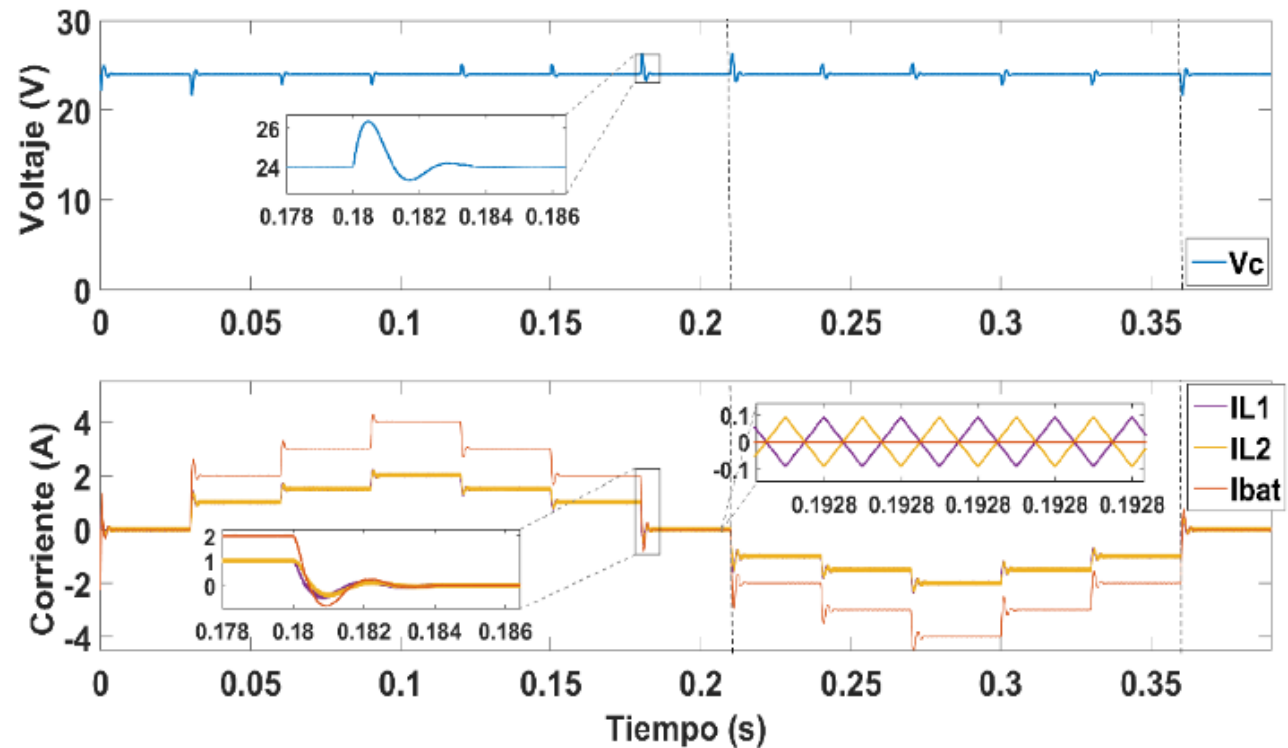

Figura 6. Estructura simplificada de la arquitectura de la implementación del algoritmo de control sobre el microcontrolador TMS320F28335. Fuente: elaboración propia.

El algoritmo de control comprende la programación de (12) a (16), las cuales incluyen el cálculo de los tres errores, la multiplicación de las constantes encontradas en el diseño y el almacenamiento de los cálculos $e_{i_{1,2}}(n-1), d_{1,2}(n-1), e_{v}(n-1)$ y $i_{L_{r e f}}(n-1)$ para su uso en las siguientes iteraciones del algoritmo de control. El resultado de este proceso es el cálculo de los ciclos útiles de cada una de las ramas, las cuales, por medio del módulo EPWM (por sus siglas en inglés, Enhance Pulse Width Modulator), generan las señales de control del convertidor.

Finalmente, los módulos ADC y EPWM se configuran para sincronizar el muestreo de las señales con el cambio en el flanco del PWM por medio del bloque SOC (por sus siglas en inglésStart Of Conversion) del conversor análogo, de esta forma se realiza un muestreo del valor máximo y el valor mínimo del rizado como se puede observar en la Figura 7, con los cuales se calcula el valor promedio de la señal. 
Este proceso se realiza correctamente debido a los filtros anti-alising utilizados en la entrada de cada canal del ADC, los cuales son diseñados para una frecuencia de corte de $200 \mathrm{kHz}$, el cual permite eliminar el ruido de alta frecuencia y evitar las deformaciones en la señal muestreada.
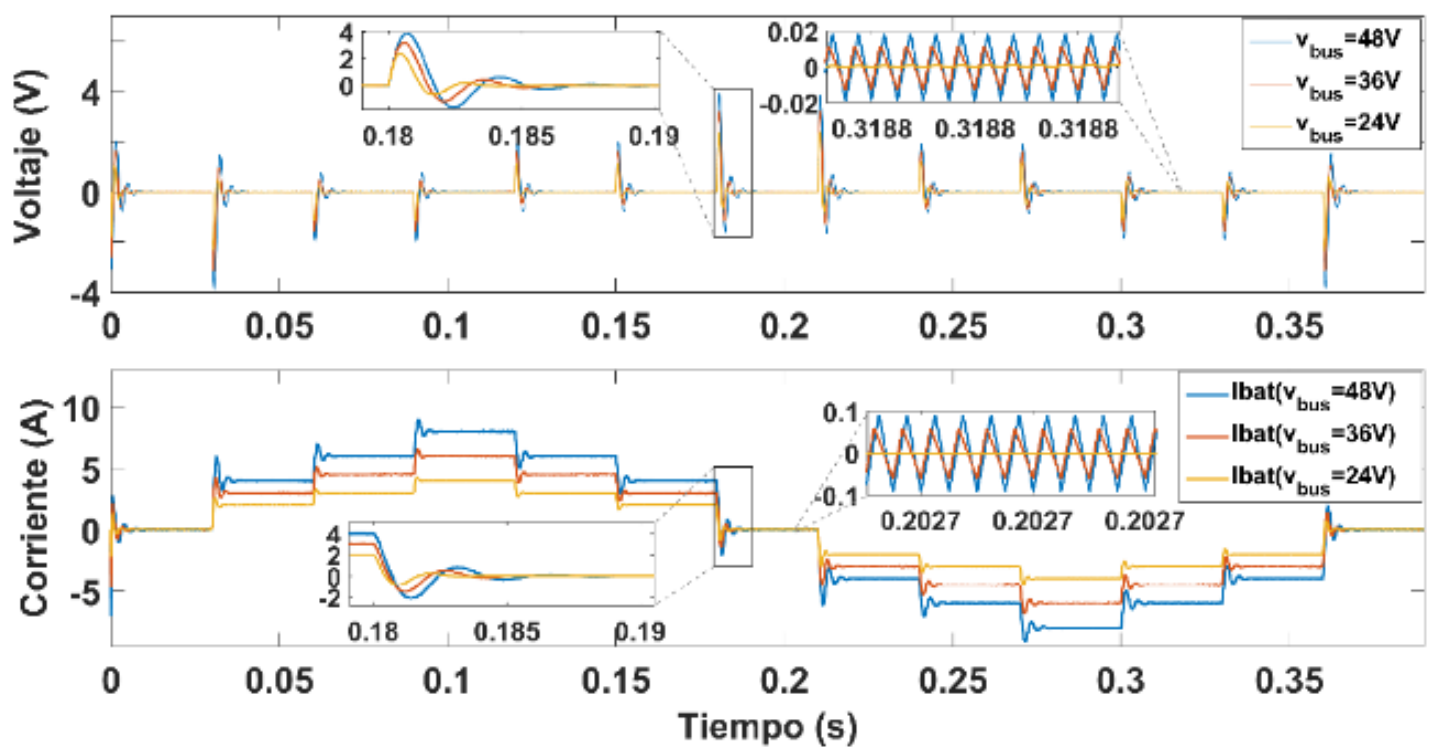

Figura 7. Sincronización de los instantes de muestreo de las corrientes de las ramas con la señal PWM Fuente: elaboración propia.

\subsection{Plataforma experimental}

El convertidor utilizado en las pruebas experimentales es diseñado para trabajar como un elevador convencional o en modo entrelazado, permitiendo de esta forma generar una comparación con los mismos parámetros como las pérdidas de conmutación, valores efectivos en los elementos, pérdidas de conducción en los elementos, pistas y soldaduras del circuito, las cuales pueden variar de una implementación a otra. Los parámetros del convertidor son presentados en la Tabla 1, el cual tiene una eficiencia de $88 \%$ en las dos configuraciones de operación.

La Figura 8 muestra la plataforma utilizada, donde se han utilizado 8 baterías de Litio conectadas en una serie de 4 paralelos de dos celdas, configuración conocida como "4S2P". Cada celda tiene un voltaje nominal de $3.6 \mathrm{~V}$ y una capacidad de $2.6 \mathrm{Ah}$, obteniendo de esta forma un pack completo de $14.6 \mathrm{~V}$ y una capacidad de $5.2 \mathrm{Ah}$.

El dispositivo de carga/descarga utilizado está comprendido por dos convertidores elevadores en configuración entrelazado. El capacitor de salida tiene una capacitancia de $44 \mathrm{uF}$ y los inductores tienen una inductancia de $330 \mathrm{uH}$ con referencia 2318-V-RC. Los dispositivos de conmutación utilizados son MOSFET de referencia IRF3710 [32], cuya señal de conmutación proviene del control de voltaje y corriente implementado en el microcontrolador de 32 bits TMS320F28335 para cada una de las respectivas ramas del control, las cuales son previamente amplificadas por el driver HIP4081A [33].

Adicionalmente, por medio de resistencias shunt de $5 \mathrm{~m} \Omega$ [33] y los sensores AD8210 es posible medir las corrientes del convertidor. Para este control se utilizan las medidas de corriente en el inductor de ambas ramas del convertidor y la medición del voltaje a la salida, la cual se realiza por medio de un divisor de voltaje e igualmente, realimentado a la tarjeta de control. 
Tabla 1. Parámetros del convertidor de prueba. Fuente: Elaboración propia.

\begin{tabular}{|c|c|c|c|c|}
\hline Parámetro & Min & Nominal & Max & Descripción \\
\hline Voltaje de entrada & $0 \mathrm{~V}$ & $48 \mathrm{~V}$ & $100 \mathrm{~V}$ & $\begin{array}{l}\text { Su valor máximo se restringe por el VDSS del } \\
\text { transistor IRF } 3710 .\end{array}$ \\
\hline Voltaje de salida & $0 \mathrm{~V}$ & $24 \mathrm{~V}$ & $63 \mathrm{~V}$ & $\begin{array}{l}\text { El voltaje máximo de salida es de } 63 \mathrm{~V} \text { debido al } \\
\text { capacitor. }\end{array}$ \\
\hline Corriente & $0 \mathrm{~A}$ & $5.2 \mathrm{~A}$ & $8 \mathrm{~A}$ & $\begin{array}{l}\text { La corriente del convertidor es limitada por la } \\
\text { capacidad del inductor. }\end{array}$ \\
\hline Potencia de entrada & $0 \mathrm{~W}$ & $249.6 \mathrm{~W}$ & $800 \mathrm{~W}$ & $\begin{array}{l}\text { El producto del voltaje y la corriente, tomando } \\
\text { los valores MIN, NOMNAL y MAX } \\
\text { respectivamente. }\end{array}$ \\
\hline Potencia de salida & $0 \mathrm{~W}$ & & $504 \mathrm{~W}$ & $\begin{array}{l}\text { El producto del voltaje y la corriente, tomando } \\
\text { los valores MIN, NOMNAL y MAX } \\
\text { respectivamente. }\end{array}$ \\
\hline Frecuencia & $10 \mathrm{kHz}$ & $100 \mathrm{kHz}$ & $1 \mathrm{MHz}$ & $\begin{array}{l}\text { La frecuencia de trabajo del convertidor es } \\
\text { establecida por el Driver de los Mosfets y los } \\
\text { mosfets. }\end{array}$ \\
\hline Ciclo de trabajo & $20 \%$ & $50 \%$ & $80 \%$ & $\begin{array}{l}\text { Los valores MIN y MAX se establecen por } \\
\text { criterio de diseño por leyes de conversión. }\end{array}$ \\
\hline $\begin{array}{l}\text { Temperatura de } \\
\text { operación }\end{array}$ & $-55^{\circ} \mathrm{C}$ & $25^{\circ} \mathrm{C}$ & $105^{\circ} \mathrm{C}$ & $\begin{array}{l}\text { Los valores MIN y MAX se establecen por el } \\
\text { aislante (esmalte) del inductor. }\end{array}$ \\
\hline
\end{tabular}

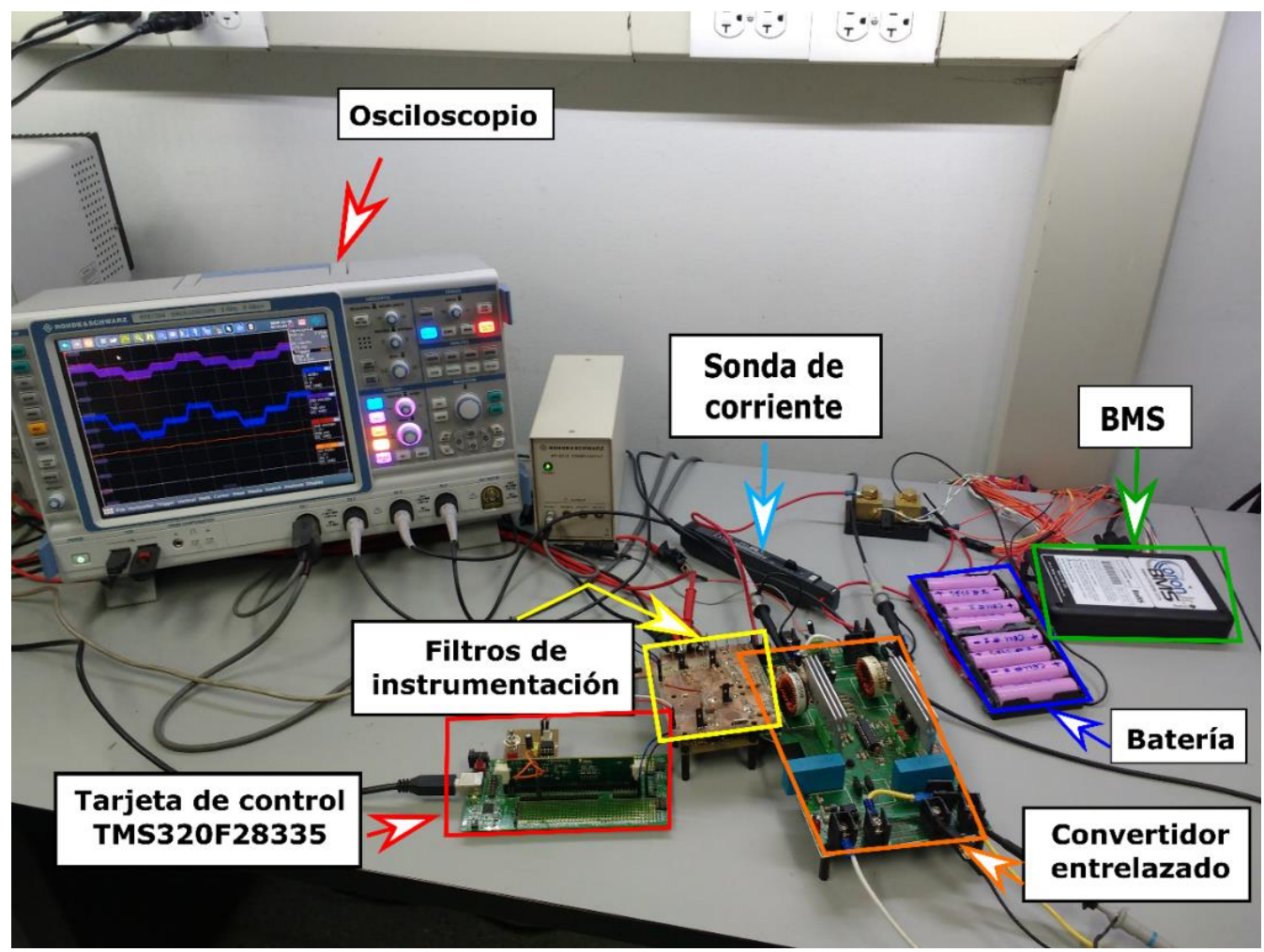

Figura 8. Plataforma de pruebas para convertidor entrelazado. Fuente: elaboración propia.

Para la simulación de los cambios de demanda e inyección de energía, se conectan en paralelo la carga electrónica BK PRECISION 8601 y una fuente programable BK PRECISION XLN6024 con un diodo de protección. A partir de estos dos equipos se emulan 
tres posibles casos con transiciones entre cada uno de estos cada 50ms: i) (modo stand-by) no existe intercambio de potencia entre la batería y el bus DC, ii) (modo carga con 1 A desde el bus DC) existe exceso de energía y puede ser almacenada en la batería y iii) (modo descarga a 1 A desde el bus DC) hay déficit de energía y es necesario utilizar la energía almacenada en la batería.

Las Figura 9, Figura 10 y Figura 11 presentan la respuesta del convertidor entrelazado para referencias de voltaje en el bus DC de $24 \mathrm{~V}, 36 \mathrm{~V}$ y $48 \mathrm{~V}$, respectivamente. En las tres figuras se presentan (señal roja) la medición de la corriente del inductor $i_{L 1}$ por el sensor AD8210, (señal naranja) voltaje a la salida del convertidor, (señal morada) voltaje de la batería, (señal azul oscura) respuesta del convertidor entrelazado para el perfil de prueba, (señal azul clara) respuesta para el mismo perfil de un convertidor elevador convencional. Es de notar, que el sistema de control digital del convertidor elevador clásico es diseñado siguiendo el mismo procedimiento del convertidor entrelazado y los mismos parámetros de tiempo de establecimiento y sobreimpulso, con el fin de proporcionar una comparación equivalente tanto para el circuito como las estrategias de control.

En las tres figuras se puede observar la regulación del voltaje del bus para los tres modos de operación, igualmente el uso del convertidor entrelazado presenta una disminución en el sobreimpulso de la corriente y un tiempo de establecimiento menor comparado con la respuesta del convertidor convencional.

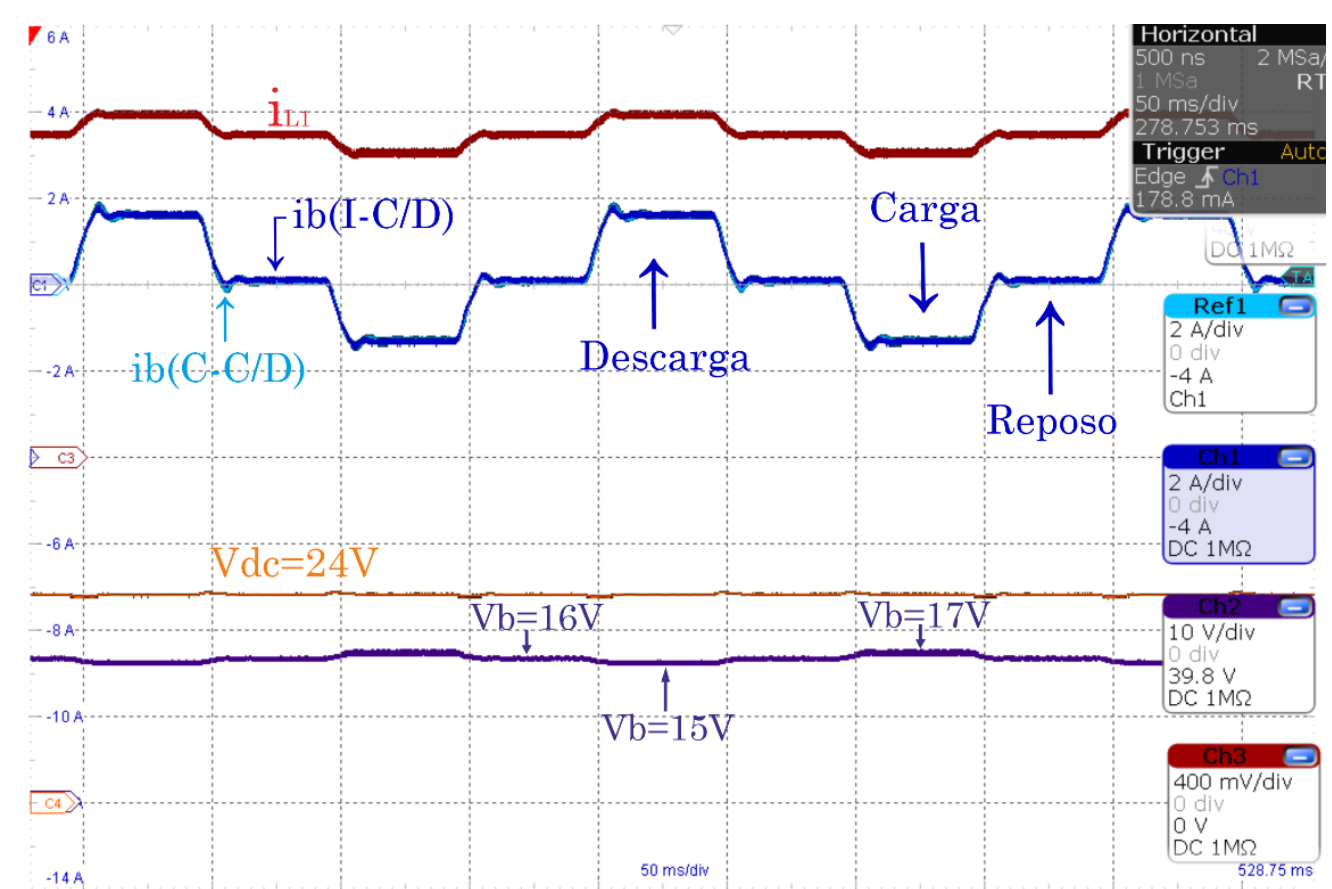

Figura 9. Comparación de las respuestas en corriente del convertidor entrelazado y un convertidor elevador convencional para una referencia de voltaje de $24 \mathrm{~V}$. Fuente: elaboración propia.

Adicionalmente, y como objetivo principal del convertidor entrelazado, se logra una disminución en el rizado de la corriente de la batería como se puede ver en la Figura 12 para una referencia de 24 V. En la Figura 13 se puede ver con mayor detalle la reducción de rizado para las tres referencias de voltaje, donde se puede observar que para un voltaje de referencia mayor el rizado de corriente aumenta. Igualmente, se observa que el rizado en el convertidor entrelazado (señal azul oscura) tiene un rizado mucho mayor que el presentado por el convertidor convencional, lo cual permite extender el tiempo de vida de la batería. 


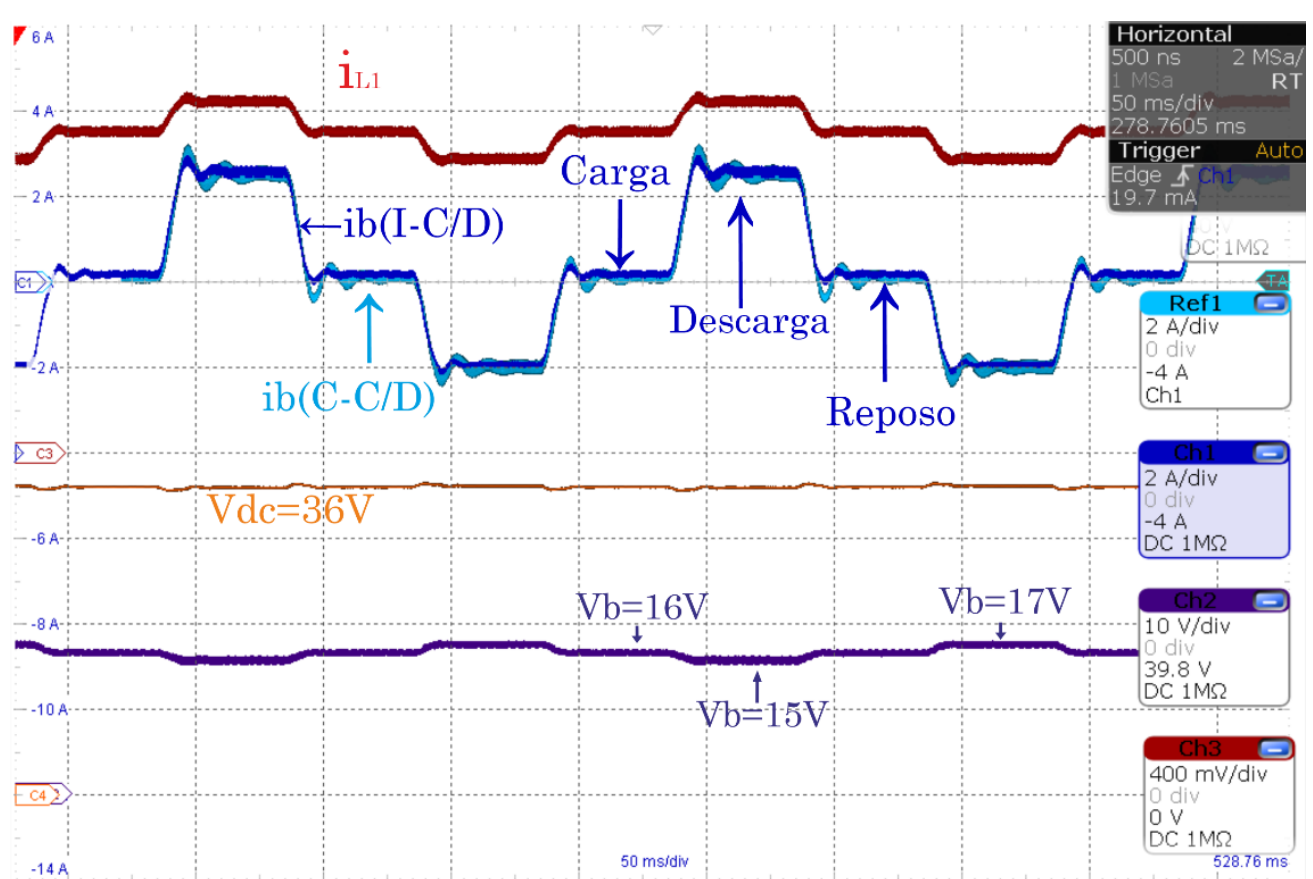

Figura 10. Comparación de las respuestas en corriente del convertidor entrelazado y un convertidor elevador convencional para una referencia de voltaje de $36 \mathrm{~V}$, Fuente: elaboración propia.

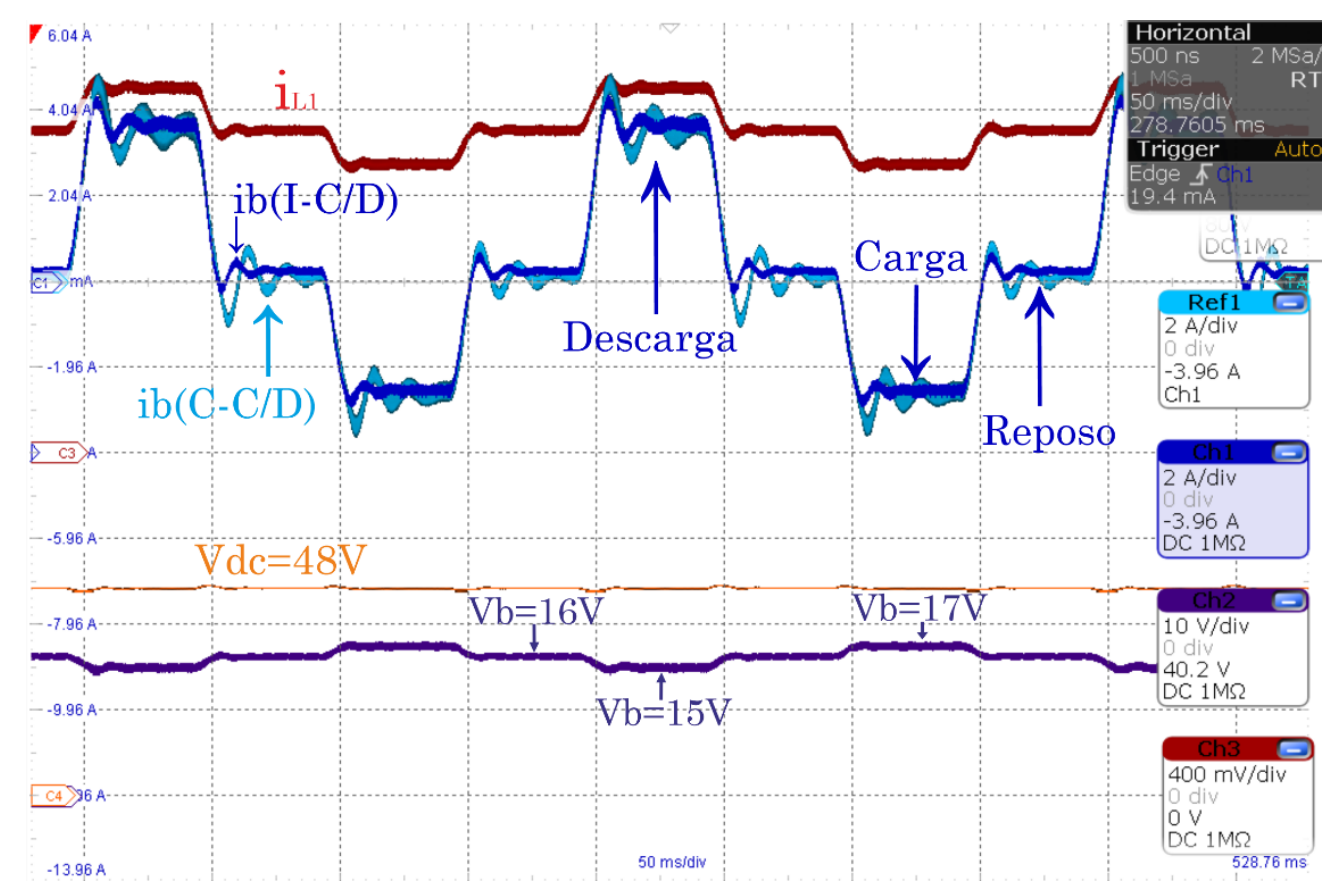

Figura 11. Comparación de las respuestas en corriente del convertidor entrelazado y un convertidor elevador convencional para una referencia de voltaje de $48 \mathrm{~V}$, Fuente: elaboración propia. 


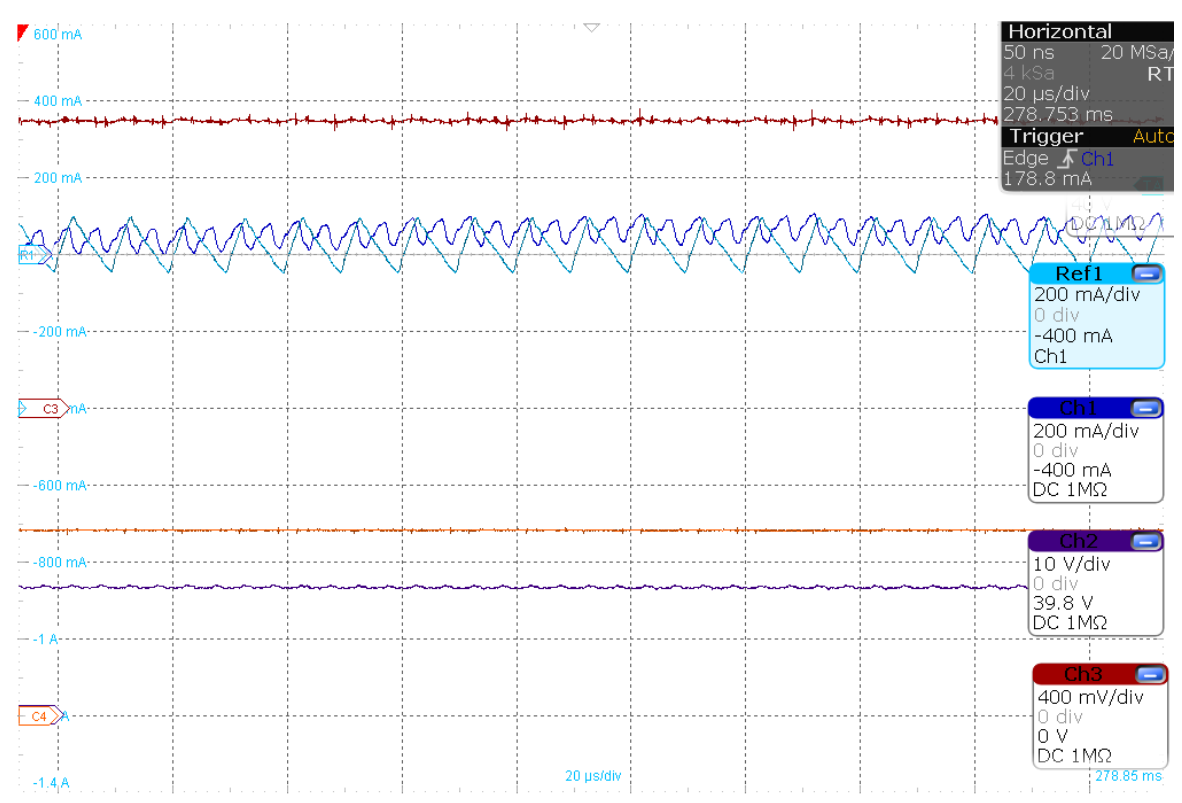

Figura 12. Comparación del rizado de un convertidor elevador y un convertidor elevador entrelazado para una referencia de voltaje en el bus DC de $24 \mathrm{~V}$, Fuente: elaboración propia.

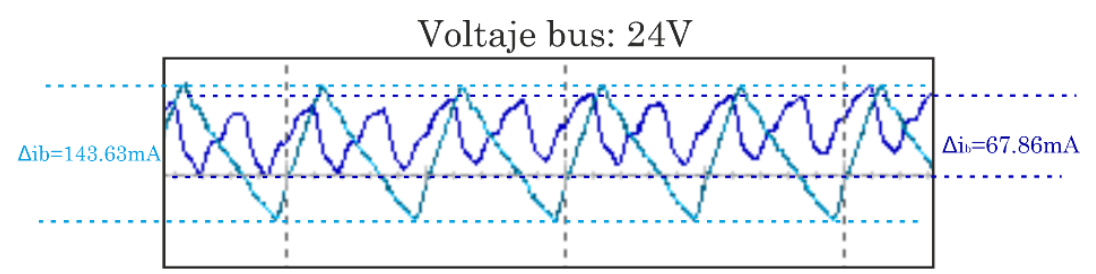

Reducción de rizado de corriente: $52.75 \%$

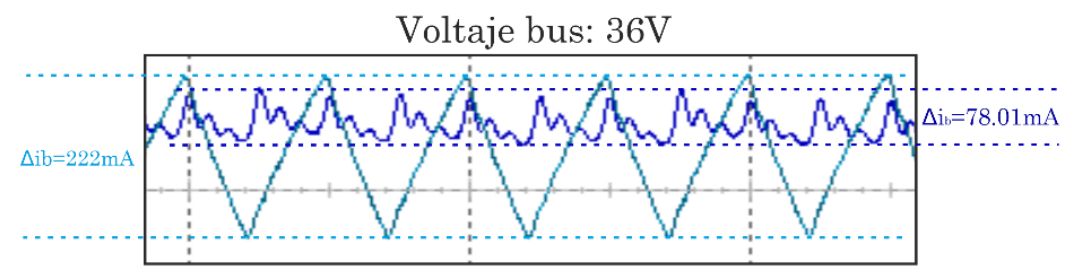

Reducción de rizado de corriente: $64.86 \%$

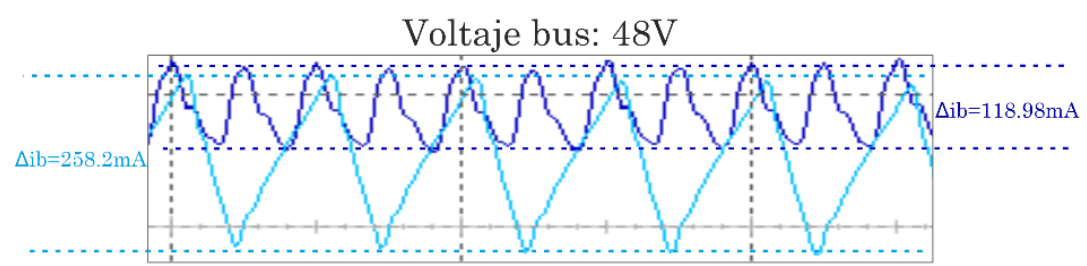

Reducción de rizado de corriente: 53.91\%

Figura 13. Comparación del rizado de un convertidor elevador entrelazado y un convertidor elevador convencional. Fuente: elaboración propia. 


\section{CONCLUSIONES}

Este trabajo presentó el modelo y control de un convertidor bidireccional entrelazado, y su implementación como sistema de regulación de carga y descarga de baterías. Adicionalmente, se presentó una estrategia de control de la segunda rama de control que permite despreciar los problemas de desbalance presentes en la implementación de los convertidores debidos a las tolerancias en los componentes y diferencias en las resistencias parásitas en el diseño del circuito impreso del dispositivo electrónico.

Este sistema permite disminuir tanto el rizado de corriente en el dispositivo almacenador de energía como en el voltaje del bus DC, permitiendo de esta forma proteger la vida útil de la batería y de las fuentes y cargas conectadas al sistema.

Finalmente, se concluye que a pesar de que el sistema tiene una correcta regulación para los puntos de evaluación, es importante contar con un control de estructura variable que permita siempre obtener el mismo sobreimpulso, tiempo de establecimiento y el mínimo rizado posible para diferentes voltajes de referencia.

\section{AGRADECIMIENTOS}

Esta investigación se desarrolló en el marco del programa jóvenes investigadores e innovadores 2019 del Instituto Tecnológico Metropolitano a quienes agradecemos por la financiación del joven investigador Cristian Escudero en su proceso de formación.

\section{CONFLICTOS DE INTERÉS DE LOS AUTORES}

Los autores no declaran conflictos de interés.

\section{CONTRIBUCIÓN DE LOS AUTORES}

Para el desarrollo de este proyecto todos los autores han realizado una contribución significativa especificada a continuación:

Cristian Escudero Quintero: pruebas experimentales y redacción de los resultados obtenidos.

Santiago Acevedo: construcción de la plataforma experimental y validación de su funcionamiento.

Juan Pablo Villegas Ceballos: conceptualización de la estrategia de control y su aplicación al sistema de baterías. Simulación y programación de la estrategia diseñada.

Daniel González Montoya: conceptualización de la técnica de control y modelado del convertidor entrelazado.

Sergio I. Serna Garcés: análisis de las soluciones encontradas en el estado del arte. Escritura del estado del arte y revisión del manuscrito final.

\section{REFERENCIAS}

[1] F. Slah; A. Mansour; M. Hajer; B. Faouzi, "Analysis, modeling and implementation of an interleaved boost DC-DC converter for fuel cell used in electric vehicle," Int. J. Hydrogen Energy, vol. 42, no. 48, pp. 2885228864, Nov. 2017. https://doi.org/10.1016/j.ijhydene.2017.08.068 
[2] P. Thounthong; S. Raël; B. Davat, "Energy management of fuel cell/battery/supercapacitor hybrid power source for vehicle applications," J. Power Sources, vol. 193, no. 1, pp. 376-385, Aug. 2009. https://doi.org/10.1016/j.jpowsour.2008.12.120

[3] S. Bashash; H. K. Fathy, "Transport-Based Load Modeling and Sliding Mode Control of Plug-In Electric Vehicles for Robust Renewable Power Tracking," IEEE Trans. Smart Grid, vol. 3, no. 1, pp. 526-534, Mar. 2012. https://doi.org/10.1109/tsg.2011.2167526

[4] S. I. Serna-Garcés, "Contributions to the efficiency and safety of stand-alone DC microgrids," (Tesis Doctoral), Universidad Nacional de Colombia, Manizalez, Colombia, 2018. URL

[5] J. Li; M. A. Danzer, "Optimal charge control strategies for stationary photovoltaic battery systems," $J$. Power Sources, vol. 258, pp. 365-373, Jul. 2014. https://doi.org/10.1016/j.jpowsour.2014.02.066

[6] M. A. Hannan; F. A. Azidin; A. Mohamed, "Hybrid electric vehicles and their challenges: A review," Renew. Sustain. Energy Rev., vol. 29, pp. 135-150, Jan. 2014. https://doi.org/10.1016/j.rser.2013.08.097

[7] C. Pillot, "Battery Market Development for Consumer Electronics, Automotive, and Industrial: Materials Requirements \& Trends," in $5^{\text {th }}$ Israeli Power Sources Conference 2015, Israel, pp. 1-40. URL

[8] M. R. Palacin; A. de Guibert, "Why do batteries fail?," Science, vol. 351, no. 6273, pp. 1253292-1253292, Feb. 2016. https://doi.org/10.1126/science.1253292

[9] O. Erdinc; B. Vural; M. Uzunoglu, "A dynamic lithium-ion battery model considering the effects of temperature and capacity fading," in 2009 International Conference on Clean Electrical Power, Capri. 2009, pp. 383-386. https://doi.org/10.1109/iccep.2009.5212025

[10] X. Liu; S. Qin; Y. He; X. Zheng; C. Cao, "SOC estimation of the lithium-ion battery with the temperaturebased Nernst model," in 2016 IEEE 8th International Power Electronics and Motion Control Conference (IPEMC-ECCE Asia), Hefei. 2016, pp. 1419-1422. https://doi.org/10.1109/IPEMC.2016.7512498

[11] C. A. Ramos-Paja; A. J. Saavedra-Montes; J. D. Bastidas-Rodríguez, "Cargador de baterías fotovoltaico con control por modos deslizantes y limitación de la derivada de corriente de carga," TecnoLógicas, vol. 21, no. 42, pp. 129-145, May. 2018. https://doi.org/10.22430/22565337.784

[12] M. Uno; K. Tanaka, "Influence of High-Frequency Charge-Discharge Cycling Induced by Cell Voltage Equalizers on the Life Performance of Lithium-Ion Cells,” IEEE Trans. Veh. Technol., vol. 60, no. 4, pp. 1505-1515, May. 2011. https://doi.org/10.1109/TVT.2011.2127500

[13] S.-C. Huang; K.-H. Tseng; J.-W. Liang; C.-L. Chang; M. Pecht, "An Online SOC and SOH Estimation Model for Lithium-Ion Batteries,” Energies, vol. 10, no. 4, p. 512, Apr. 2017. https://doi.org/10.3390/en10040512

[14] P. A. Topan; M. N. Ramadan; G. Fathoni; A. I. Cahyadi; O. Wahyunggoro, "State of Charge (SOC) and State of Health (SOH) estimation on lithium polymer battery via Kalman filter," in 2016 2nd International Conference on Science and Technology-Computer (ICST), Yogyakarta. 2016, pp. 93-96. https://doi.org/10.1109/ICSTC.2016.7877354

[15] M.-H. Hung; C.-H. Lin; L.-C. Lee; C.-M. Wang, "State-of-charge and state-of-health estimation for lithiumion batteries based on dynamic impedance technique," J. Power Sources, vol. 268, pp. 861-873, Dec. 2014. https://doi.org/10.1016/j.jpowsour.2014.06.083

[16] H. Rahimi-Eichi; U. Ojha; F. Baronti; M.-Y. Chow, "Battery Management System: An Overview of Its Application in the Smart Grid and Electric Vehicles," IEEE Ind. Electron. Mag., vol. 7, no. 2, pp. 4-16, Jun. 2013. https://doi.org/10.1109/mie.2013.2250351

[17] S. Serna-Garcés; D. Gonzalez Montoya; C. Ramos-Paja, "Sliding-Mode Control of a Charger/Discharger DC/DC Converter for DC-Bus Regulation in Renewable Power Systems," Energies, vol. 9, no. 4, p. 245, Mar. 2016. https://doi.org/10.3390/en9040245

[18] S. Serna-Garcés; D. González Montoya; C. Ramos-Paja, "Control of a Charger/Discharger DC/DC Converter with Improved Disturbance Rejection for Bus Regulation,” Energies, vol. 11, no. 3, pp. 594, Mar. 2018. https://doi.org/10.3390/en11030594

[19] J. P. Villegas Ceballos; S. I. Serna-Garcés; D. González Montoya; C. A. Ramos-Paja; J. D. BastidasRodríguez, "Charger/discharger DC/DC converter with interleaved configuration for DC-bus regulation and battery protection," Energy Sci. Eng., vol. 8, no. 2, pp. 530-543, Feb. 2020. https://doi.org/10.1002/ese3.534

[20] M. A. Devi; K. Valarmathi; R. Mahendran, "Ripple current reduction in interleaved boost converter by using advanced PWM techniques," in 2014 IEEE International Conference on Advanced Communications, Control and Computing Technologies, Ramanathapuram. 2014, pp. 115-119. https://doi.org/10.1109/icaccct.2014.7019291

[21] K. Siri; C. Q. Lee; T.-E. Wu, "Current distribution control for parallel connected converters. I," IEEE Trans. Aerosp. Electron. Syst., vol. 28, no. 3, pp. 829-840, Jul. 1992. http://dx.doi.org/10.1109/7.256303

[22] R. Giral; L. Martinez-Salamero; S. Singer, "Interleaved converters operation based on CMC," IEEE Trans. Power Electron., vol. 14, no. 4, pp. 643-652, Jul. 1999. https://doi.org/10.1109/63.774201

[23] D. J. Perreault; J. G. Kassakian, "Distributed interleaving of paralleled power converters," IEEE Trans. Circuits Syst. I Fundam. Theory Appl., vol. 44, no. 8, pp. 728-734, Aug. 1997. 
http://dx.doi.org/10.1109/81.611269

[24] S. Vijayalakshmi; E. Arthika; G. S. Priya, "Modeling and simulation of interleaved Buck-boost converter with PID controller," in 2015 IEEE 9th International Conference on Intelligent Systems and Control (ISCO), Coimbatore. 2015, pp. 1-6. http://dx.doi.org/10.1109/ISCO.2015.7282392

[25] H. M. M. Swamy; K. P. Guruswamy; S. P. Singh, "Design, Modeling and Analysis of Two Level Interleaved Boost Converter," in 2013 International Conference on Machine Intelligence and Research Advancement, Katra. 2013, pp. 509-514. https://doi.org/10.1109/ICMIRA.2013.107

[26] M. Habib; F. Khoucha; A. Harrag, "GA-based robust LQR controller for interleaved boost DC-DC converter improving fuel cell voltage regulation,” Electr. Power Syst. Res., vol. 152, pp. 438-456, Nov. 2017. https://doi.org/10.1016/j.epsr.2017.08.004

[27] R. Giral; L. Martinez-Salamero; R. Leyva; J. Maixe, "Sliding-mode control of interleaved boost converters," IEEE Trans. Circuits Syst. I Fundam. Theory Appl., vol. 47, no. 9, pp. 1330-1339, 2000. http://dx.doi.org/10.1109/81.883328

[28] R. W. Erickson; D. Maksimović, Fundamentals of Power Electronics 2nd. ed. . Springer Science \& Business Media, 2007.

[29] B. C. Kuo, Automatic control systems. Upper Saddle River, NJ. Prentice Hall PTR, 1987.

[30] T. I. Inc., "TMS320F2833x, TMS320F2823x Digital Signal Controllers (DSCs)," Dallas, TX, USA, 2016. URL

[31] I. Rectifier, "IRF3710PbF HEXFET® Power MOSFET," California, USA, 2010. URL

[32] Renesas Electronics Corporation, "HIP4081A, 80V High Frequency H-Bridge Driver," Milpitas, California, Estados Unidos. URL

[33] A. Device, "High Voltage, Bidirectional Current Shunt Monitor," Norwood, Massachusetts,USA, 2017. $\underline{\mathrm{URL}}$ 